\title{
Tumor-derived trypsin enhances proliferation of intrahepatic cholangiocarcinoma cells by activating protease-activated receptor- 2
}

\author{
SHIN-ICHI NAKANUMA ${ }^{1,4}$, HIDEHIRO TAJIMA ${ }^{1}$, KOUICHI OKAMOTO ${ }^{1}$, HIRONORI HAYASHI ${ }^{1}$, \\ HISATOSHI NAKAGAWARA ${ }^{1}$, ICHIRO ONISHI ${ }^{1}$, HIROYUKI TAKAMURA ${ }^{1}$, HIROHISA KITAGAWA ${ }^{1}$, \\ SACHIO FUSHIDA ${ }^{1}$, TAKASHI TANI ${ }^{1}$, TAKASHI FUJIMURA ${ }^{1}$, MASATO KAYAHARA ${ }^{1}$, \\ TETSUO OHTA ${ }^{1}$, TOMOHIKO WAKAYAMA ${ }^{2}$, SHOICHI ISEKI ${ }^{2}$ and SHIN-ICHI HARADA ${ }^{3}$
}

\author{
Departments of ${ }^{1}$ Gastroenterologic Surgery, and ${ }^{2}$ Histology and Embryology and \\ ${ }^{3}$ Center for Biomedical Research, Kanazawa University Graduate School of Medical Science, \\ Takara-machi 13-1, Kanazawa 920-8641, Japan
}

Received October 27, 2009; Accepted December 3, 2009

DOI: 10.3892/ijo_00000555

\begin{abstract}
In primary malignant liver tumors, trypsinogenimmunoreactivity was present in $70 \%$ of intrahepatic cholangiocarcinoma (ICC) specimens, but absent in hepatocellular carcinoma (HCC) specimens. We suggest the secretion of trypsinogen to be a key difference in biological behavior between ICC and HCC cells. The purpose of this study was to investigate the secretion of tumor-derived trypsin and the expression of its specific receptor, protease-activated receptor-2 (PAR-2), in ICC using cell lines and surgical specimens. The expression of trypsinogen-1 mRNA was observed in three of four ICC cell lines, but none of three HCC cell lines. Western blot analysis detected trypsinogen-1 in serum-free conditioned medium from one of the ICC cell lines positive for the mRNA. Gelatin zymography revealed a gelatinolytic activity for trypsin, the activated form of trypsinogen, in the same conditioned medium. PAR-2 mRNA and protein were observed in ICC cell lines. The proliferative activity of ICC cells was increased by concentrations of trypsin as low as $10 \mathrm{nM}$, and peaked at $100 \mathrm{nM}$. The effect of trypsin was suppressed by a serine protease inhibitor, gabexate mesilate. PAR-2 expression was detected in $64 \%$ of ICC surgical specimens immunohistochemically. In addition, stroma fibroblasts expressed PAR-2 in 52\% of ICC specimens. These results suggest that trypsinogen- 1 contributes to the growth of ICC cells and also tumor-associated fibroblasts.
\end{abstract}

Correspondence to: Dr Shin-ichi Nakanuma, ${ }^{4}$ Present address: Department of Surgery, Kanazawa Social Insurance Hospital, Ha-15, Oki-machi, Kanazawa 920-8610, Japan

E-mail: nakanuma@kanazawa-shaho.com

Key words: trypsin, trypsinogen, protease-activated receptor-2, intrahepatic cholangiocarcinoma, hepatocellular carcinoma, gabexate mesilate

\section{Introduction}

Both intrahepatic cholangiocarcinoma (ICC) and hepatocellular carcinoma (HCC) are primary malignant liver tumors. ICC is relatively rare, despite being the second most common primary hepatic malignancy after HCC. It reportedly comprises only $5-10 \%$ of primary liver neoplasms (1). Even though both these tumor types spread into hepatic parenchyma, they differ in biological behavior. Clinically, ICC frequently recurs despite surgical curative resection $(2,3)$ and adjuvant chemotherapy (4), and has a poor prognosis compared with HCC (5). Histologically, ICC is an adenocarcinoma showing tubular or papillary structures with a variable fibrous stroma $(6,7)$ (Fig. 1A), while HCC consists of tumor cells that resemble hepatocytes (7) (Fig. 1B). The scirrhous type characterized by marked fibrosis is uncommon in HCC (7). We predict that there is an essential difference in growth and progression between ICC and HCC correlated with each cancer cellular characteristics.

Trypsinogen is a digestive enzyme produced by pancreatic acinal cells, and is one of the serine proteases. Trypsin, the activated form of trypsinogen, has the characteristics of activating matrix metalloproteases and also possesses gelatinolytic activity (8). Previous studies have shown that a variety of cancer cell lines and cancer tissues express this enzyme (9-13). Koshikawa et al identified 1- and 2-chain forms of trypsinogen-1 (cationic trypsinogen) in a gastric carcinoma cell line (14). Under acidic conditions that prevail in the extracelluar space between malignant tumor cells, trypsinogen-1 is spontaneously converted to trypsin (15). We previously reported that when a pancreatic cancer cell line that lacked expression of trypsinogen mRNA was transfected with trypsinogen-1 cDNA, the cells secreted trypsinogen and acquired significantly greater invasive ability (16). In addition, we demonstrated in pancreatic cancer cell lines that hepatic metastasis and invasive ability were correlated with the amount of trypsinogen-1 and were inhibited by a serine protease inhibitor (17). Thus, trypsin 
plays an essential role in facilitating the invasion and metastasis of the cancer cells.

Previous studies have described protease-activated receptor-2 (PAR-2) as one of the G protein-coupled receptors that is activated by trypsin (18-20). PAR-2 activation induces a number of physiologic processes, and its agonist, trypsin is considered a signaling molecule (21). PAR-2 expression has been found in certain human solid tumors, such as gastric, colon and pancreatic cancer (22-26). Furthermore, several studies have suggested that trypsin plays a pivotal role in proliferation and serves as a potent mitogen in PAR2-positive cancer cells (22-26). The proliferative effect of the PAR-2 signal is mediated by the MEK-MAP kinase cascade $(23,27)$.

With regard to ICC and HCC, $70 \%$ of ICC specimens expressed trypsinogen but the immunoreactivity was absent in HCC specimens (28). Therefore, we suggest that the relationship between trypsinogen secreted by the cancer cells and its specific receptor, PAR-2, might contribute to the proliferation of ICC cells, revealing a difference in biological behavior between ICC and HCC. Thus, in this study, we examined whether ICC cells secrete trypsinogen- 1 and express PAR-2 protein using tissue specimens and cell lines. We also investigated whether the proliferation of ICC cells expressing PAR-2 was enhanced by trypsin.

\section{Materials and methods}

ICC and HCC specimens. ICC specimens: between December 1998 and October 2008, 25 patients with ICC underwent surgical resection at the Kanazawa University Hospital. ICC was defined as an intrahepatic cholangiocarcinoma without any detectable extrahepatic primary tumor. Of the 25 patients, 14 were men and 11 were women, with a mean age of 64.3 (range: $35-84$ ) years. The gross appearance of the cut surface of ICC was categorized into the following types according to the Liver Cancer Study Group of Japan classification system for Primary Liver Cancer (29): mass forming (MF), periductal infiltrating (PI), intraductal growth (IG) and other. Of the 25 patients, $16(64 \%)$ had the MF type of ICC, six (24\%) had the MF + PI type, two (8\%) had the PI type and one (4\%) had the IG type. HCC specimens: between September 2001 and August 2006, 148 patients with HCC underwent surgical resection at the Kanazawa University Hospital. We selected 15 of the 148 patients at random: 11 men and 4 women, with a mean age of 65.7 (range: 52-77) years.

Cell lines and culture conditions. Four ICC cell lines (HuCCT-1, IHGGK and HuH28 from the Cell Resource Center for Biochemical Research, Tohoku University, Sendai, Japan; and CCKS-1 from the Department of Human Pathology, Kanazawa University, Kanazawa, Japan) and three HCC cell lines (HuH7 from the Cell Resource Center for Biochemical Research; HepG2 from the Bioresource Center, Tsukuba, Japan; and HLE from the Health Science Research Resources Bank, JCRB Cellbank, Tokyo, Japan) were used. CCKS-1, HuCCT-1, IHGGK and HuH28 cells were maintained in RPMI-1640 medium (Nissui Pharmaceutical, Tokyo, Japan), whereas HepG2, HLE and HuH7 cells were maintained in Dulbecco's modified Eagle's medium (Invitrogen Corporation, Tokyo, Japan) supplemented with $2 \mathrm{mM}$ glutamine (Nissui
Pharmaceutical), 10\% fetal bovine serum (FBS) (Nichirei Biosciences Inc., Tokyo, Japan), $100 \mathrm{U} / 1$ penicillin and $100 \mu \mathrm{g} /$ $\mathrm{ml}$ streptomycin (Invitrogen Corporation, Tokyo, Japan) at $37^{\circ} \mathrm{C}$ in a $5 \% \mathrm{CO}_{\mathrm{s}}$ incubator.

Antibodies. As primary antibodies, we used a mouse antitrypsin monoclonal antibody (Nihon Millipore K.K., Tokyo, Japan), and a mouse anti-PAR-2 monoclonal antibody (Santa Cruz, CA, USA).

Chemicals. Active trypsin (trypsin from bovine pancreas, sequencing grade for biochemistry) was obtained from Wako Pure Chemical Industries (Tokyo, Japan).

Immunohistochemistry. Immunostaining of surgically resected ICC and HCC tissues was performed on $10 \%$ formalin-fixed, paraffin-embedded samples using a streptavidin-biotinperoxidase method. Briefly, $4 \mu$ m-thick sections were mounted on poly-L-lysine-coated glass slides, air-dried, and deparaffinized with graded xylene and alcohol solutions. After treatment by microwave, endogenous peroxidase activity was suppressed with $0.3 \%$ hydrogen peroxide and methanol. The sections were treated with $5 \%$ hydrogen normal goat serum to block non-specific binding. They were incubated with the mouse anti-trypsin monoclonal antibody (1:300) or mouse anti-PAR-2 monoclonal antibody (1:100) overnight at $4{ }^{\circ} \mathrm{C}$. The sections were rinsed in PBS and incubated with biotinylated anti-mouse IgG (Dako Envision System, Dako Japan, Kyoto, Japan) for 60 min followed by peroxidase-labeled streptavidin (Dako Envision System) for $5 \mathrm{~min}$ at room temperature. Reaction products were developed in a $0.02 \% 3,3^{\prime}$-diaminobenzidine tetrahydrochloride solution containing $0.1 \% \mathrm{H}_{2} \mathrm{O}_{2}$ (Dako Envision System). The cells were counterstained with hematoxylin.

Immunocytochemistry. For the localization of PAR-2 in ICC cells, each cancer cell line was grown on Lab-Tec chamber slides (Nalge Nunc International, New York, NY), and then fixed in a mixture of methanol and acetone (1:1) for $15 \mathrm{~min}$. Immunostaining was performed as reported $(24,30)$. Briefly, the slides were immersed in methanol containing $0.3 \% \mathrm{H}_{2} \mathrm{O}_{2}$ for $30 \mathrm{~min}$, blocked with $3.3 \%$ normal goat serum in PBS, and incubated with the mouse anti-PAR-2 monoclonal antibody $(1: 80)$ at $4{ }^{\circ} \mathrm{C}$ overnight. After the sections were washed in PBS, the immunoreactivity was visualized by incubating the sections with anti-mouse IgG antibody conjugated with Alexa Fluor488 (Molecular Probes, Eugene, OR) (1:400) for $1 \mathrm{~h}$ at room temperature. The sections were counterstained in the nucleus with $100 \mathrm{ng} / \mathrm{ml}$ of bisbenzimide H33258 (Hoechst 33258) (Sigma-Aldrich, St. Louis, MO). They were then observed with an immunofluoresence microscope (BX50/BX-FLA, Olympus, Tokyo, Japan).

Reverse transcription-polymerase chain reaction (RT-PCR). Total RNA was isolated from each cancer cell line and normal pancreas tissue from surgical specimens by the acid guanidinium thiocyanate-phenol-chloroform method (31). RT-PCR was performed as described (24). The following primers were purchased from Takara Bio Inc. (Shiga, Japan): for human trypsinogen-1 (32), forward 5'-ACCACCATGAATCCACC 
A

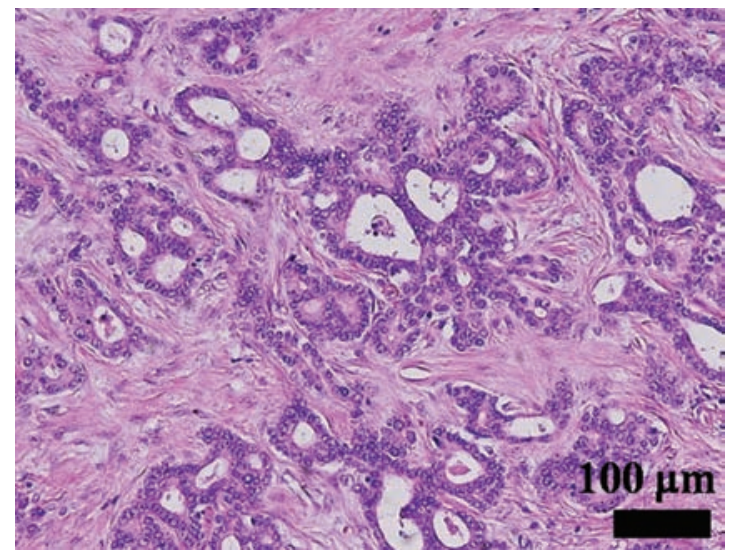

B

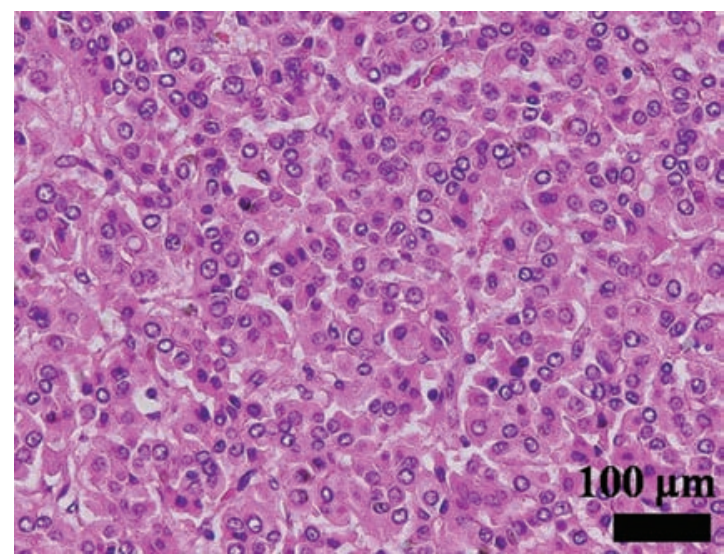

Figure 1. Histological finding of H\&E for ICC (A) and HCC (B). (A) ICC is an adenocarcinoma showing tubular or papillary structures with a variable fibrous stroma. (B) HCC consists of tumor cells that resemble hepatocytes.

ACTCCTG-3' and reverse 5'-GCTTTAGCTATTGGCA GCTAT-3'; for PAR-2, forward 5'-CTGACCTCCTCTC TGTCATC-3' and reverse 5'-GGACAGTGACAATGA GTTTG-3'; and for glyceraldehyde-3-phosphate dehydrogenase (GAPDH), forward 5'-ACCACAGTCCATGCCA TCAC-3' and reverse 5'-TCCACCACCCTGTTGCTGTA-3'. Amplification of GAPDH was used as a control for sample loading and integrity. The conditions for using Ex Tag polymerase (Takara Bio Inc.) were: denaturation at $94^{\circ} \mathrm{C}$ for $30 \mathrm{sec}$, annealing at $54^{\circ} \mathrm{C}$ for $1 \mathrm{~min}$, and extension at $72^{\circ} \mathrm{C}$ for 1 min a total of 38 times for trypsinogen-1, and 35 times for PAR-2 and GAPDH.

Gelatin zymography. The preparation and concentration of serum-free conditioned media were performed as reported (14). Briefly, cells were grown to semiconfluence in $100 \mathrm{~mm}$ dishes containing $10 \mathrm{ml}$ of RPMI-1640 medium supplemented with $10 \%$ FBS. The culture was washed twice with PBS and then replaced with serum-free RPMI-1640 medium. After 5 days, the culture medium was titrated with $1 \mathrm{~N} \mathrm{HCl}$ to $\mathrm{pH} 5.5$ or 6.5 , because trypsinogen- 1 is spontaneously converted to trypsin under acidic conditions $(8,15)$. Then the medium was incubated at $37^{\circ} \mathrm{C}$ for $3 \mathrm{~h}$. The resulting supernatant was concentrated 50 times using Vivaspin 4 (Sartorius Stedim Biotech $\mathrm{GmbH}$, Goettingen, Germany). The conditioned medium was processed for gelatin zymography as described previously $(10,33)$. Gelatinolytic bands were visualized by staining with
Coomassie Brilliant Blue R-250 after incubation in $50 \mathrm{mM}$ Tris- $\mathrm{HCl}$ (pH 7.5) containing $5 \mathrm{mM} \mathrm{CaCl}_{2}$ at $37^{\circ} \mathrm{C}$ for $20 \mathrm{~h}$.

Western blot analysis. Western blotting was performed as described (24). The same conditioned medium was used as in gelatin zymography. The protein concentration of each sample was measured using a BCA protein assay kit (Thermo Scientific, Yokohama, Japan). For SDS-PAGE, $20 \mu \mathrm{g}$ of protein from each sample was loaded on a $5-20 \%$ gradient polyacrylamide gel (e-PAGEL, Atto Corporation, Tokyo, Japan). Proteins were transferred to PVDF membranes (BioRad Laboratories, Hercules, CA), then blocked with commercial gradient buffer (EzBlock, Atto Corporation) at room temperature for $30 \mathrm{~min}$. The membrane was incubated with the mouse anti-trypsin antibody (1:1000) or mouse antiPAR-2 antibody (1:100) as the primary antibody at room temperature for $1 \mathrm{~h}$. After being washed with commercial gradient buffer (EzWash, Atto Corporation), the membrane was incubated with a horseradish peroxidase-conjugated antimouse IgG antibody (ECL Plus Western blotting reagent reagent pack (Amersham, Little Chalfont, UK) for $1 \mathrm{~h}$ at room temperature. Detection of chemiluminescence was performed with the ECL Plus Western blotting reagent detection system (Amersham).

Cell growth assay. The proliferative effect of active trypsin on ICC cell lines was quantified using the MTS assay according to the manufacturer's instructions. CCKS-1 cells $\left(0.5 \times 10^{4} /\right.$ well $)$ were grown in 96 -well plates in medium with $10 \%$ FBS for $48 \mathrm{~h}$. The medium was then removed and the cells were subsequently incubated in serum-free medium containing different concentrations $(0.1$ to $100 \mathrm{nM})$ of active trypsin or $10 \%$ FBS for $72 \mathrm{~h}$. Briefly, at the end of the period of exposure to trypsin, $20 \mu \mathrm{l}$ of the MTS reagent (CellTiter 96 aqueous solution, Promega, Madison, WI) was added to $100 \mu 1$ of medium in each well. Cells were further cultured for $3 \mathrm{~h}$ and the resultant absorbance was recorded at $490 \mathrm{~nm}$ using a 96-well plate reader (EAR 340 AT, SLT, Vienna, Austria).

In some experiments, the proliferation assay was carried out in the presence of both $100 \mathrm{nM}$ active trypsin and different concentrations of a serine protease inhibitor, gabexate mesilate (FOY-007, Ono Pharmaceutical Co., Osaka, Japan). Cancer cells were seeded on 96-well plates in medium with $10 \%$ FBS for $48 \mathrm{~h}$. The cells were exposed to $100 \mathrm{nM}$ active trypsin and a concentration of gabexate mesilate $(0.01$ to $1 \mathrm{mM})$ for 3 days. The number of cells was counted using the MTS assay.

Data represent the mean \pm SD from three different experiments and are expressed as a percentage of the number of cells in untreated controls.

Statistical analysis. Statistical analyses were carried out using Student's unpaired t-test. $\mathrm{p}<0.05$ was considered statistically significant.

\section{Results}

Detection of tumor-derived trypsinogen/trysin in ICC and HCC tissues. In 13 of the 25 ICC surgical specimens (54\%), 
A

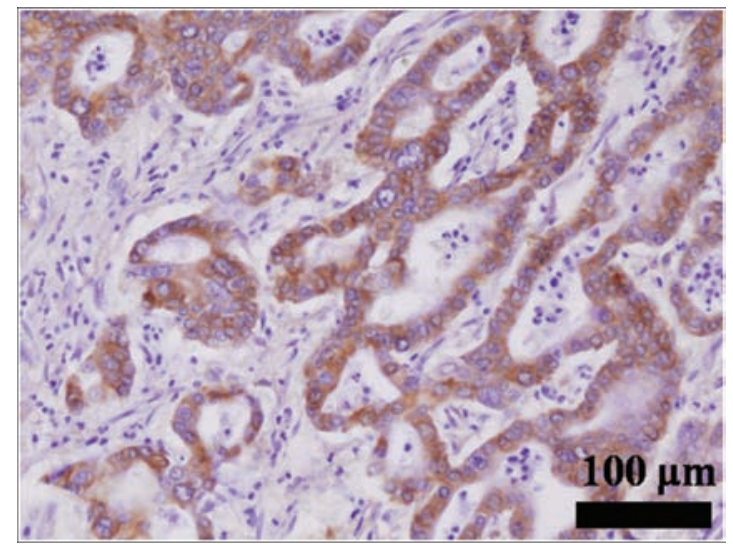

B

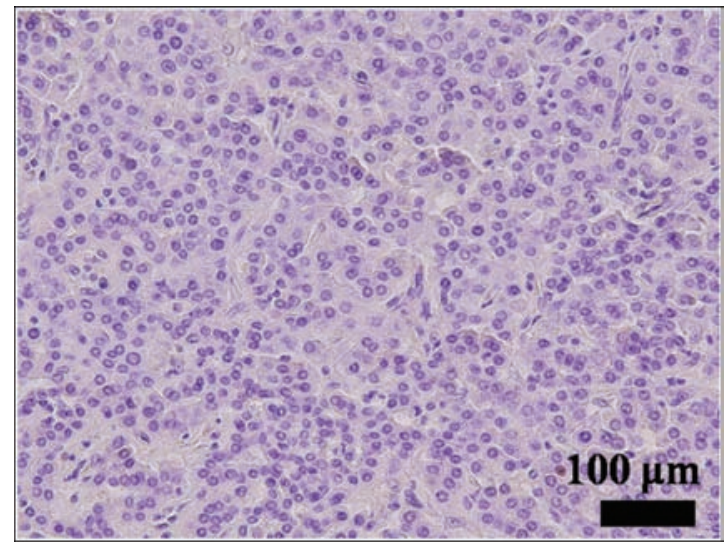

Figure 2. Immunohistochemical staining for trypsin in ICC (A) and HCC (B) tissues. (A) Trypsin was evident in ICC cancer cells which showed tubular structures. (B) HCC tissues. There was no staining in HCC cells.

trypsin was detected in $>10 \%$ of carcinoma cells by immunohistochemistry (Fig. 2A). Trypsin-immunoreactivity was evident throughout the cytoplasm of ICC cells. In addition, trypsin was weakly expressed in the ICC cancer stroma. However, trypsin was not detected in HCC tissues (Fig. 2B). These results are consistent with those of our previous study (28).

Expression of tripsinogen-1 mRNA in ICC and HCC cell lines. A RT-PCR analysis of trypsinogen-1 was conducted with the ICC and HCC cell lines. Normal pancreas tissue was used as a positive control. Trypsinogen-1 expression at the mRNA level was observed in three of the four ICC cell lines, HUCCT-1, CCKS-1, and HuH28, but none of the three HCC cell lines (Fig. 3). These results confirm that trypsinogen-1 mRNA was expressed specifically in ICC cell lines.

The secretion of tumor-derived trypsinogen/trypsin in the supernatant of cultured ICC cells. To examine whether trypsinogen-1 was secreted extracellularly and convertible to the active form trypsin, we performed Western blotting and gelatin zymography with serum-free conditioned medium prepared from an ICC cell line, CCKS-1, positive for trypsinogen-1 mRNA. The Western blot analysis revealed two bands at 23 and $25 \mathrm{kDa}$ (Fig. 4). These bands were well consistent with those reported for the activated forms of 2- and 1-chain trypsinogen-1, respectively (14). Gelatin zymography

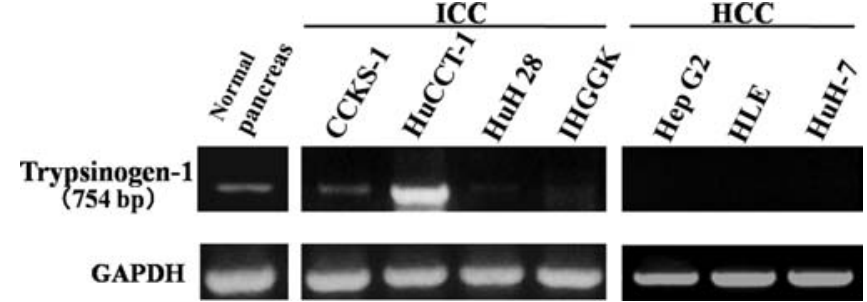

Figure 3. RT-PCR analysis of ICC and HCC cell lines for trypsinogen-1. Three ICC cell lines, CCKS-1, HuCCT-1 and HuH28, expressed trypsinogen-1. One of the ICC cell lines, IHGGK, and the three HCC cell lines, HepG2, HLE and HuH-7, did not express this enzyme. Normal human pancreas was used as a positive control. Amplification of GAPDH gene expression was used as a control for sample loading and integrity.

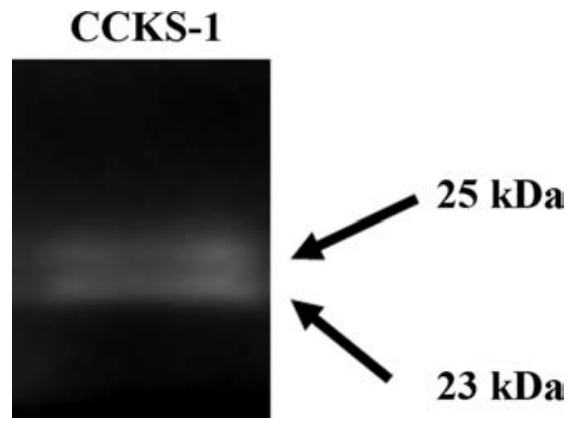

Figure 4. Western blot analysis for trypsin secreted into the medium from CCKS-1 cells (positive for trypsinogen-1 mRNA). The medium showed two bands (23 and $25 \mathrm{kDa}$ ) well consistent with the activated forms of 2- and 1chain trypsinogen-1.

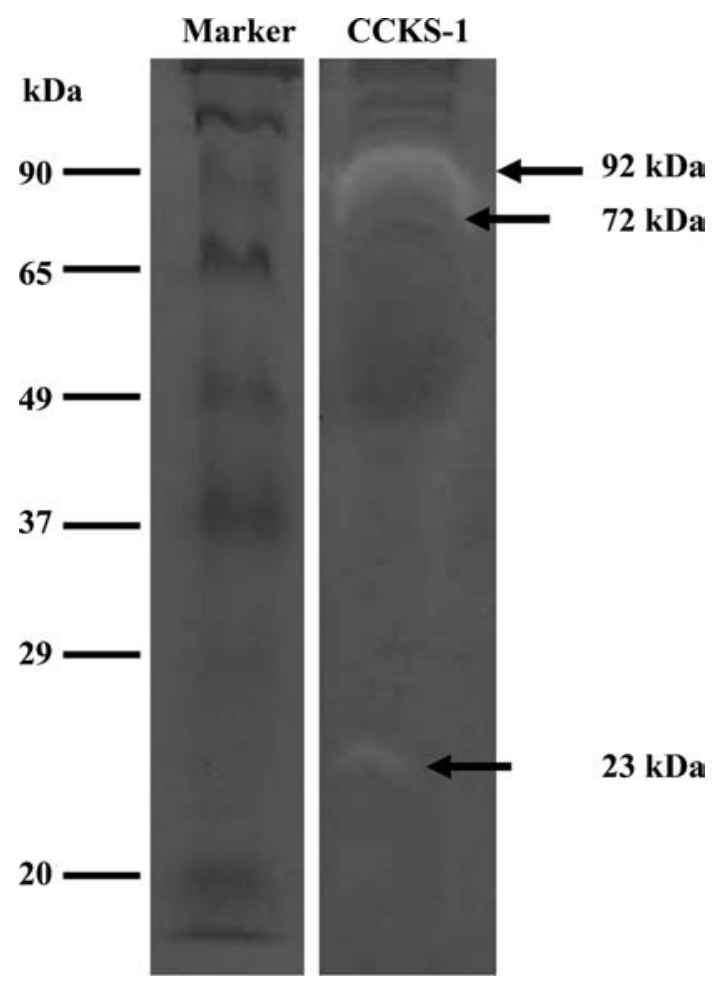

Figure 5. Zymographic analysis for proteolytic enzymes secreted into the medium from CCKS-1 cells (positive for trypsinogen-1 mRNA). Gelatinolytic activity at a molecular weight of $\sim 23 \mathrm{kDa}$ corresponding to trypsin appeared in the conditioned medium of CCKS-1 cells. Additional gelatinolytic activity, consistent with MMP-2 (72 kDa) and MMP-9 (92 kDa), was present in the same medium. 


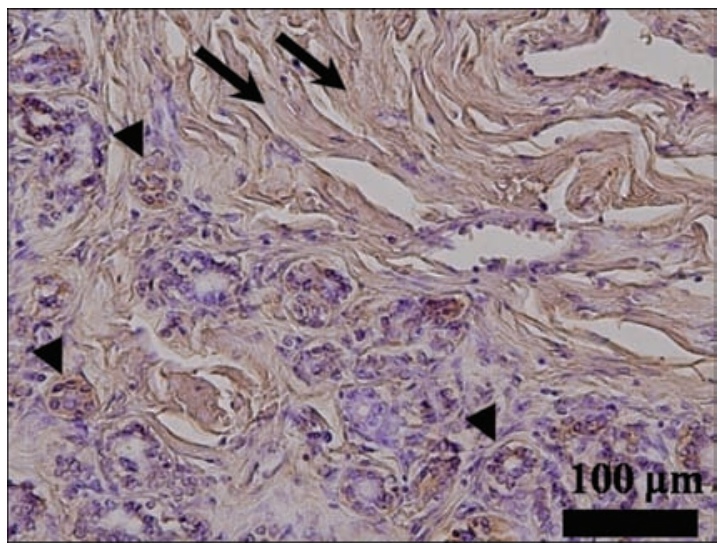

Figure 6. Immunohistochemical staining for PAR-2 in ICC tissues. ICC cells (arrowheads) and stromal fibroblasts (arrows) expressed PAR-2. The immunostaining of PAR-2 was diffuse in the cytoplasma of ICC cells. ICC stromal fibroblasts were also homogeneously positive for PAR-2.

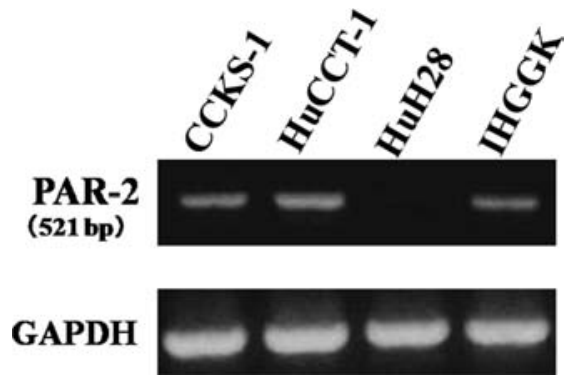

Figure 7. RT-PCR analysis of ICC cell lines for PAR-2. Three ICC cell lines, CCKS-1, HuCCT-1 and IHGGK, expressed PAR-2. One of the ICC cell lines, HuH28, did not express PAR-2. Amplification of the GAPDH gene was used as a control for sample loading and integrity.

showed a gelatinolytic band with a molecular weight of $\sim 23-25 \mathrm{kDa}$ corresponding to trypsin (Fig. 5). This band was consistent with that reported for the activated form of trypsinogen-1 $(14,16)$. In addition, the supernatant exhibited gelatinolytic activity with bands at $\sim 72$ and $92 \mathrm{kDa}$. Similar bands were reported previously: the first protease corresponding to MMP-2, the second, to MMP-9 (34). There was no difference in the results whether the medium was titrated to pH 5.5 or 6.5 (data not shown).

Detection of PAR-2 expression in ICC tissues. In 17 of the 25 ICC surgical specimens (68\%), PAR-2 was detected in $>10 \%$ of carcinoma cells by immunohistochemistry (Fig. 6). PAR-2-immunoreactivity was evident throughout the cytoplasm of ICC cells. In addition, the cancer stroma showed expression of PAR-2 in 13 of the 25 ICC specimens (52\%) (Fig. 6).

Expression of PAR-2 $m R N A$ and protein in ICC cell lines. We examined the expression of PAR- 2 mRNA in ICC cell lines using RT-PCR. The mRNA was observed in three of four ICC cell lines, HUCCT-1, CCKS-1, and IHGGK (Fig. 7). To quantify the expression of PAR-2 protein, we

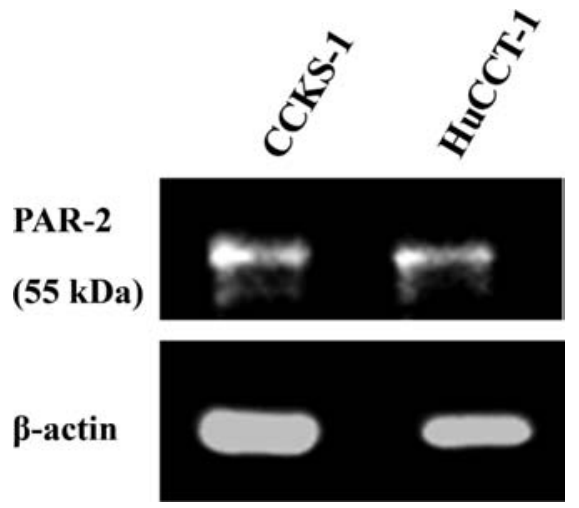

Figure 8. Western blot analysis of ICC cell lines (positive for PAR-2 mRNA) for PAR-2. Two ICC cell lines, CCKS-1 and HuCCT-1, showed a band of $\sim 55 \mathrm{kDa}$ corresponding to the known molecular weight of PAR-2.

A

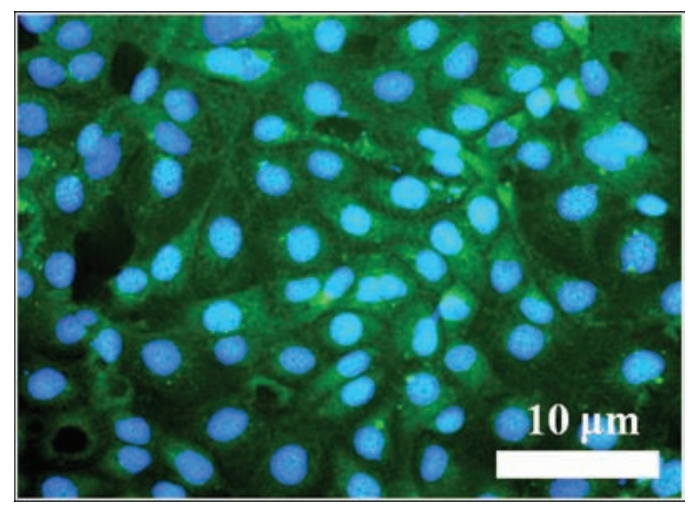

B

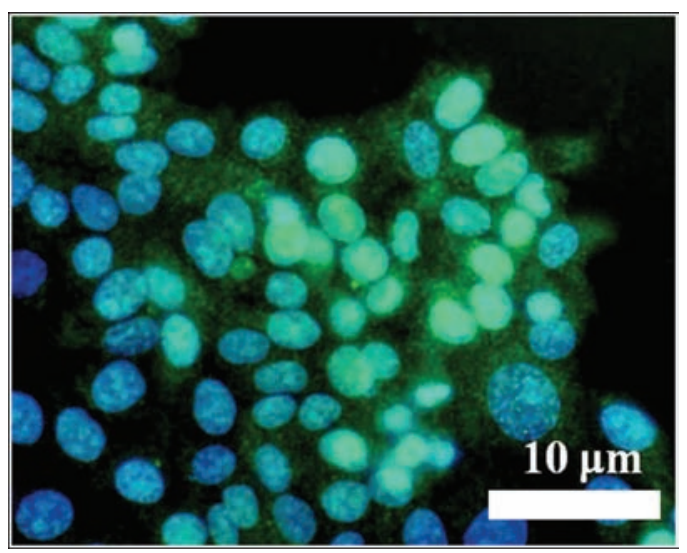

Figure 9. Fluorescence immunocytochemistry for PAR-2 in ICC cell lines. CCKS-1 (A) and HuCCT-1 (B) were incubated with anti-PAR-2 monoclonal antibody. PAR-2-immunoreactivity (green) was present predominantly in the cytoplasm in both cell lines.

performed Western blot analysis using a specific monoclonal antibody against human PAR-2. Two ICC cell lines, CCKS-1 and HuCCT-1 which expressed PAR-2 mRNA, showed a band of $\sim 55 \mathrm{kDa}$ corresponding to the known molecular weight of PAR-2 (Fig. 8).

Expression and cellular localization of PAR-2 protein in ICC cell lines. To confirm the cellular localization of PAR-2 in ICC cell lines, we performed immunofluorescence microscopy using the mouse anti-PAR-2 antibody and negative 


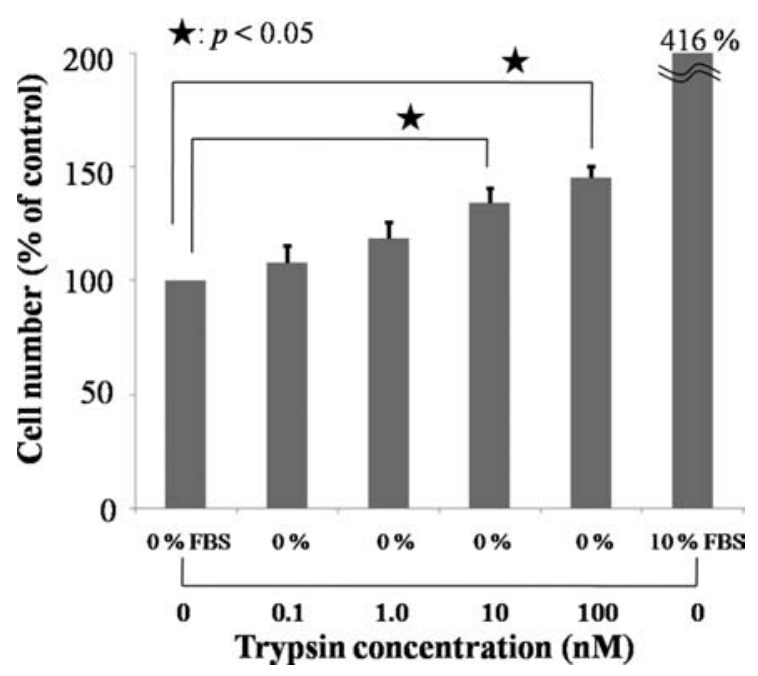

Figure 10. ICC cancer cells were treated with different concentrations (0.1-100 nM) of PAR-2 activator, trypsin or 10\% FBS, and the proliferative effect was quantified by the MTS assay. Trypsin induced a dosedependent increase in proliferative activity. The graph shows representative data for CCKS-1 cells. Results are the mean \pm SD for three different experiments.

control antibodies. Cancer cells were detected by the presence of blue nuclei, PAR-2-immunoreactivity was green. PAR-2 was intense in both CCKS-1 (Fig. 9A) and HuCCT-1 (Fig. 9B) cells and was observed in the entire cytoplasm. These results were consistent with the level of PAR-2 expression determined by Western blotting.

Effect of trypsin on the growth of ICC cell lines. To examine the effect of the PAR-2 activator, trypsin, on the growth of ICC cells, CCKS-1 was treated with either active trypsin ( 0.1 to $100 \mathrm{nM}$ ) or $10 \% \mathrm{FBS}$, and proliferative activity was quantified by the MTS assay. In CCKS-1 cells which showed immunoreactivity to PAR-2, 3 days of treatment with active trypsin induced a significant increase in cell number (Fig. 10). The MTS assay showed a dose-dependent increase in proliferative activity, and the effect induced by $100 \mathrm{nM}$ active trypsin was almost $35 \%$ of that induced by $10 \%$ FBS. At higher concentrations $(\geq 1 \mu \mathrm{M})$, the cancer cells detached from the plastic culture dishes, and the proliferation assay was no longer reliable.

In addition, we determined whether trypsin-induced proliferation in ICC cells was inhibited by gabexate mesilate, a potent inhibitor of serine protease. CCKS- 1 cells were cultured with various concentrations of gabexate mesilate for 3 days, and cell numbers were counted by the MTS assay. Gabexate mesilate completely inhibited the $100 \mathrm{nM}$ trypsin-induced proliferative response at a concentration of $0.1 \mathrm{mM}$ (Fig. 11). Recent studies found that gabexate mesilate at $0.01 \mathrm{mM}$ and $0.1 \mathrm{mM}$ did not have a significant effect on the proliferation of colon and pancreatic cancer cell lines, whereas at a concentration of $1 \mathrm{mM}$, the number of cells was markedly reduced after 3 days of culture $(35,36)$. Therefore, we suggested that gabexate mesilate $(0.01$ and $0.1 \mathrm{mM})$ had no cytotoxic effect. These results demonstrate that the suppressive effect of gabexate mesilate on cell growth resulted from inhibition of trypsin, not from non-specific cytotoxicity.

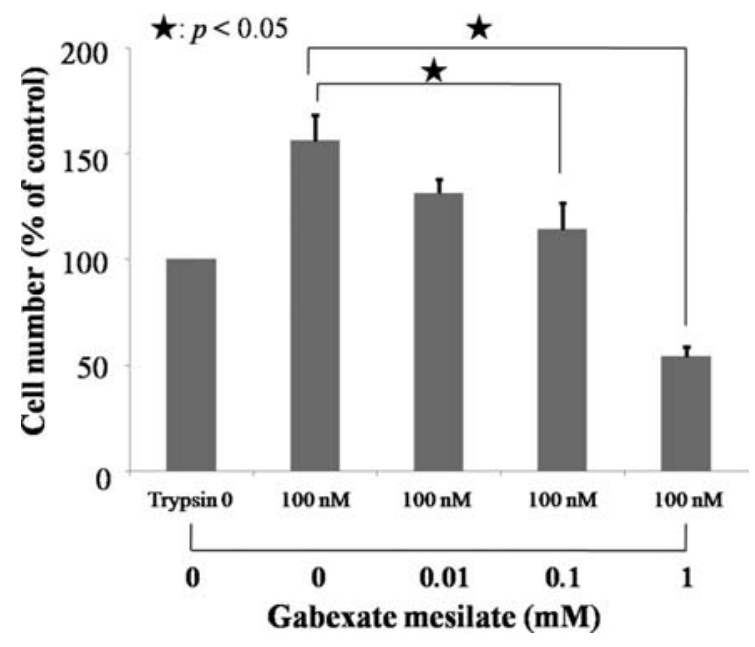

Figure 11. Effect of gabexate mesilate, a potent inhibitor of serine protease, on the trypsin-induced proliferative response. Gabexate mesilate completely inhibited the $100 \mathrm{nM}$ trypsin-induced proliferative response at a concentration of $0.1 \mathrm{mM}$ in CCKS-1. Results are the mean $\pm \mathrm{SD}$ for three different experiments.

\section{Discussion}

Active trypsin, produced and secreted by cancer cells, plays an essential role in facilitating invasion and metastasis by digesting components of the extracellular matrix $(8-14,16,17)$. At the same time, the contribution of PAR-2 and the effect of active trypsin on signaling pathways influencing malignant tumors are still being studied (22-27). With regard to tumorderived trypsin in primary malignant liver tumors, our previous study demonstrated trypsinogen immunoreactivity in ICC tissues but not in HCC tissues (28), and Lempinen et al (37) suggested that serum trypsinogen-2 was a useful marker for diagnosing patients with cholangiocarcinoma, superior to serum CA19-9 and CEA. However, the secretion of trypsinogen in primary malignant liver tumors is still unknown. Furthermore, PAR-2 expression in primary malignant liver tumors has not been examined.

In the present study, we showed that trypsinogen-1 was secreted in serum-free conditioned medium of an ICC cell line by Western blotting and detected active trypsin by gelatin zymography in the same medium. On the other hand, by RTPCR, the expression of trypsinogen-1 was not detectable in HCC cell lines. In addition, PAR- 2 was detected in ICC cell lines by RT-PCR and Western blotting. Also, ICC cell lines showed PAR-2-immunoreactivity throughout the cytoplasm. We further demonstrated that trypsin at a concentration as low as $10 \mathrm{nM}$ enhanced proliferative activity in ICC cells. The activity peaked at a concentration of $100 \mathrm{nM}$. These results are consistent with those in our previous study on PAR-2positive pancreatic cancer cell lines (24). The enhanced proliferation was suppressed by gabexate mesilate, a potent inhibitor of serine protease. Given that trypsin induced the proliferation of PAR-2-positive human pancreatic, colon, gastric, breast and cervical cancers in vitro (22-27), we suggest that trypsin secreted by ICC cells has the same effect on PAR-2-positive ICC cells in an autocrine manner. This study is the first indication of the enhancement of proliferative 
activity by trypsin in PAR-2-positive ICC cells. These results show the secretion of trypsinogen to represent a novel difference in biological behavior between ICC and HCC.

ICC shows a variable fibrous stroma, but $74.2 \%$ of ICCs occur in normal liver (5). On the other hand, fibrotic change is uncommon in HCC, but $80.3 \%$ of HCCs arise from fibrotic liver (5). Based on these results, the degree of fibrosis in the primary liver tumor may not correlate well with the degree of fibrosis in the background hepatic parenchyma. We suggest that there is a fibrotic mechanism independent of the background hepatic parenchyma in primary liver tumor, especially in ICC. The stroma has been thought to passively support tumor development and progression, and there is increasing evidence that the stroma activity contributes to the growth and invasion of malignant tumors $(38,39)$.

In our study, PAR-2-immunoreactivity was observed in $52 \%$ of ICC stromas including tumor-associated fibroblasts. The involvement of PAR-2 in the cancer stroma has recently begun to be elucidated. Two previous studies demonstrated that stromal fibroblasts expressed PAR-2 in pancreatic cancer and breast cancer $(40,41)$. Interestingly, researchers have also reported that PAR-2 is a potential factor in the pathogenesis of several inflammatory diseases, fibrotic disease in clinical studies $(42,43)$ and experimental studies $(44,45)$. Our results suggest that in the ICC microenvironment, exposure to trypsin induced the proliferation of fibroblasts on PAR-2 stimulation, while in the non-exposed HCC microenvironment it did not. Trypsin may have not only an autocrine effect on PAR-2positive cancer cells but also a paracrine effect on PAR-2positive tumor-associated fibroblasts. Although the mechanism of fibrosis in ICC is still poorly understood, its worth investigating the influence of trypsin and PAR-2 on tumorassociated fibroblasts.

\section{References}

1. The Liver Cancer Study Group of Japan: Primary liver cancer in Japan: Clinicopathologic features and results of surgical treatment. Ann Surg 211: 277-287, 1990.

2. Ohtsuka M, Ito H, Kimura F, et al: Results of surgical treatment for intrahepatic cholangiocarcinoma and clinicopathological factors influencing survival. Br J Surg 89: 1525-1531, 2002.

3. Morimoto Y, Tanaka Y, Ito T, et al: Long-term survival and prognostic factors in the surgical treatment for intrahepatic cholangiocarcinoma. J Hepatobiliary Pancreat Surg 10: 432-440, 2003.

4. Khan SA, Thomas HC, Davidson BR and Taylor-Robinson SD: Cholangiocarcinoma. Lancet 366: 1303-1314, 2005.

5. Ikai I, Itai Y, Okita K, et al: Report of the 15th follow-up survey of primary liver cancer. Hepatol Res 28: 21-29, 2004.

6. Colombari R and Tsui WM: Biliary tumors of liver. Semi Liver Dis 15: 402-413, 1995.

7. Nakanuma Y, Sripa B and Vatanasapt V: Pathology and genetics tumours of the digestive system. In: Intrahepatic cholangiocarcinoma. Hamilton SR and Aaltonen LA (eds). WHO Press, Geneva, pp173-180, 2000.

8. Ohta T, Tajima H, Fushida S, et al: Cationic trypsinogen produced by human pancreatic ductal cancer has the characteristics of spontaneous activation and gelatinolytic activity in the presence of proton. Int J Mol Med 1: 689-92, 1998.

9. Koivunen E, Saksela O, Itkonen O, et al: Human colon carcinoma, fibrosarcoma and leukemia cell lines produce tumorassociated trypsinogen. Int J Cancer 47: 592-596, 1991.

10. Koshikawa N, Yasumitsu H, Umeda M and Miyazaki K: Multiple secretion of matrix serine proteinases by human gastric carcinoma cell lines. Cancer Res 52: 5046-5053, 1992.

11. Ohta $T$, Terada $T$, Nagakawa $H$, et al: Pancreatic trypsinogen and cathepsin B in human pancreatic carcinomas and associated metastatic lesions. Br J Cancer 69: 152-156, 1994.
12. Otha T, Terada T, Nagakawa H, et al: Differential expression of pancreatic trypsinogen and cathepsin B in human scirrhous-type and intestinal-type gastric cancer. Oncol Rep 1: 203-208, 1994.

13. Kawano N, Osawa H, Ito T, et al: Expression of gelatinase A. tissue inhibitor of metalloproteinases-2, matrilysin, and trypsin(ogen) in lung neoplasms: an immunohistochemical study. Hum Pathol 28: 613-622, 1997.

14. Koshikawa N, Yasumitsu H, Nagashima Y, Umeda M and Miyazaki K: Identification of one- and two-chain forms of trypsinogen 1 produced by a human gastric adenocarcinoma cell line. Biochem J 303: 187-190, 1994.

15. Figarella C, Miszczuk-Jamska B and Barett AJ: Possible lysosomal activation of pancreatic zymogens. Activation of both human trypsinogens by cathepsin B and spontaneous acid. Activation of human trypsinogen 1. Biol Chem Hoppe Seyler 369 (Suppl): 293-298, 1998.

16. Tajima H, Ohta T, Elnemr A, et al: Enhanced invasiveness of pancreatic adenocarcinoma cells stably transfected with cationic trypsinogen cDNA. Int J Cancer 94: 699-704, 2001.

17. Ohta $\mathrm{T}$, Futagami $\mathrm{F}$, Arakawa $\mathrm{H}$, et al: Inhibitory effect of a serine protease inhibitor, FOY-305, on the invasion and metastasis of human pancreatic cancers. Int J Oncol 11: 813-817, 1997.

18. Nystedt S, Emilsson K, Larsson AK, Strombeck B and Sundelin J: Molecular cloning and functional expression of the gene encoding the human proteinase-activated receptor 2. Eur J Biochem 232: 84-89, 1995.

19. Bohm SK, Kong W, Bromme D, et al: Molecular cloning: expression and potential functions of the human proteinaseactivated receptor-2. Biochem J 314: 1009-1016, 1996.

20. Fox MT, Harriott P, Walker B and Stone SR: Identification of potential activators of proteinase-activated receptor-2. FEBS Lett 417: 267-269, 1997.

21. Déry O, Corvera CU, Steinhoff M and Bunnett NW: Proteinaseactivated receptors: novel mechanisms of signaling by serine proteases. Am J Physiol 274: 1429-1452, 1998.

22. Miyata S, Koshikawa N, Yasumitsu H and Miyazaki K: Trypsin stimulates integrin alpha(5)beta(1)-dependent adhesion to fibronectin and proliferation of human gastric carcinoma cells through activation of proteinase-activated receptor-2. J Biol Chem 275: 4592-4598, 2000.

23. Darmoul D, Gratio V, Devaud H and Laburthe M: Proteaseactivated receptor 2 in colon cancer: trypsin-induced MAPK phosphorylation and cell proliferation are mediated by epidermal growth factor receptor transactivation. J Biol Chem 279: 20927-20934, 2004

24. Ohta T, Shimizu K, Yi S, et al: Protease-activated receptor-2 expression and the role of trypsin in cell proliferation in human pancreatic cancers. Int J Oncol 23: 61-66, 2003.

25. Matej R, Mandakova P, Netikova I, Pouckova P and Olejar T: Proteinase-activated receptor-2 expression in breast cancer and the role of trypsin on growth and metabolism of breast cancer cell line MDA MB-231. Physiol Res 56: 475-484, 2007.

26. Sánchez-Hernández PE, Ramirez-Dueñas MG, AlbarranSomoza B, et al: Protease-activated receptor-2 (PAR-2) in cervical cancer proliferation. Gynecol Oncol 108: 19-26, 2008.

27. Jikuhara A, Yoshii M, Iwagaki H, Mori S, Nishibori M and Tanaka N: MAP kinase-mediated proliferation of DLD-1 carcinoma by the stimulation of protease-activated receptor 2 . Life Sci 73: 2817-2829, 2003.

28. Terada T, Ohta T, Minato H and Nakanuma Y: Expression of pancreatic trypsinogen/trypsin and cathepsin B in human cholangiocarcinomas and hepatocellular carcinomas. Hum Pathol 26: 746-752, 1995.

29. Liver Cancer Study Group of Japan: The General Rules for the Clinical and Pathological Study of Primary Liver Cancer. 4th edition, Kanehara, pp20-21, 2000 (In Japanese).

30. Wakayama T, Sai Y, Ito A, et al: Heterophilic binding of the adhesion molecules poliovirus receptor and immunoglobulin superfamily $4 \mathrm{~A}$ in the interaction between mouse spermatogenic and Sertoli cells. Biol Reprod 76: 1081-1090, 2007.

31. Chomczynski P and Sacchi N: Single-step method of RNA isolation by acid guanidinium thiocyanate-phenol chloroform extraction. Anal Biochem 162: 156-159, 1987.

32. Emi M, Nakamura Y, Ogawa M, et al: Cloning, characterization and nucleotide sequences of two cDNAs encoding human pancreatic trypsinogens. Gene 41: 305-310, 1986.

33. Yasumitu H, Miyazaki K, Umenishi F, et al: Comparison of extracelluar matrix-degrading activities between $64-\mathrm{kDa}$ and $90-\mathrm{kDa}$ gelatinases purified in inhibitor-free forms from human schwanoma cells. J Biochem 111: 74-80, 1992. 
34. Tanriverdi-Akhisaroglu S, Menderes A and Oktay G: Matrix metalloproteinase-2 and -9 activities in human keloids, hypertrophic and atrophic scars: a pilot study. Cell Biochem Funct 27: 81-87, 2009.

35. Yoon W, Jung Y, Kim T, et al: Gabexate mesilate inhibits colon cancer growth, invasion, and metastasis by reducing matrix metalloproteinases and angiogenesis. Clin Cancer Res 10: 4517-4526, 2004.

36. Uchima Y, Sawada T and Hirakawa K: Action of antiproteases on pancreatic cancer cells. JOP 8 (Suppl 4): 479-487, 2007.

37. Lempinen M, Isoniemi H, Mäkisalo H, et al: Enhanced detection of cholangiocarcinoma with serum trypsinogen-2 in patients with severe bile duct strictures. J Hepatol 47: 677-683, 2007.

38. Chung LW: The role of stromal-epithelial interaction in normal and malignant growth. Cancer Surv 23: 33-42, 1995.

39. Pupa SM, Menard S, Forti S, et al: New insights into the role of extracellular matrix during tumor onset and progression. J Cell Physiol 190: 259-267, 2002.

40. Ikeda O, Egami H, Ishiko T, et al: Expression of proteinaseactivated receptor- 2 in human pancreatic cancer: A possible relation to cancer invasion and induction of fibrosis. Int J Oncol 22: 295-300, 2003.
41. D'Andrea MR, Derian CK, Santulli RJ and Andrade-Gordon P: Differential expression of protease-activated receptors-1 and -2 in stromal fibroblasts of normal, benign, and malignant human tissues. Am J Pathol 158: 2031-2041, 2001.

42. Cederqvist K, Haglund C, Heikkila P, et al: High expression of pulmonary proteinase-activated receptor 2 in acute and chronic lung injury in preterm infants. Pediatr Res 57: 831-836, 2005.

43. Grandaliano G, Pontrelli P, Cerullo G, et al: Protease-activated receptor-2 expression in IgA nephropathy: a potential role in the pathogenesis of interstitial fibrosis. J Am Soc Nephrol 14: 2072-2083, 2003.

44. Masamune A, Kikuta K, Satoh M, et al: Protease-activated receptor-2-mediated proliferation and collagen production of rat pancreatic stellate cells. J Pharmacol Exp Ther 312: 651-658, 2005.

45. Borensztajn K, Stiekema J, Nijmeijer S, et al: Factor Xa stimulates proinflammatory and profibrotic responses in fibroblasts via protease-activated receptor-2 activation. Am J Pathol 172: 309-320, 2008. 